\title{
Spatial and temporal patterns of habitat use by three estuarine species of mysid shrimp
}

\author{
Matthew D. Taylor ${ }^{\mathrm{A}, \mathrm{B}, \mathrm{C}}$ \\ AEvolution and Ecology Research Centre, School of Biological, Earth and Environmental Science, \\ University of New South Wales, Sydney, 2052, Australia. \\ ${ }^{B}$ Sydney Institute of Marine Science, Building 22, Chowder Bay Road, Mosman, NSW, 2088, Australia. \\ CEmail: mattytaylor@unsw.edu.au
}

\begin{abstract}
The mysids Rhopalopthalmus egregius, Haplostylus dakini and Doxomysis australiensis are abundant yet unstudied omnivorous crustaceans in Australian estuaries. Habitat use and population dynamics were investigated for these species over spring and summer in the Tweed River, Australia, to explore their ecological role in estuarine ecosystems. Overall, mysids were concentrated in shallow unvegetated and deep unvegetated estuarine habitats. $H$. dakini were most abundant in shallow and deep bare habitats at night, whereas $R$. egregius were most abundant in deep bare habitats during the night. $D$. australiensis were present across all habitats in the night, but negligible numbers were present during the day. Significantly greater numbers of $R$. egregius and $D$. australiensis were sampled during the new moon, compared with the full moon. Significantly larger $R$. egregius and $D$. australiensis individuals were present in benthic habitats at night, indicating possible partitioning of habitat for juvenile and adult subpopulations. Adaptive foraging strategies and habitat use facilitates the coexistence of sympatric mysid species, H. dakini and R. egregius, and within-species habitat partitioning allowed juvenile $R$. egregius to avoid interaction with adult $R$. egregius. The observed dynamics minimize interand intra-specific predation between mysids, and by other predators, while optimizing access to key trophic resources.
\end{abstract}

Additional keywords: diel period, habitat partitioning, lunar period, predation.

\section{Introduction}

Estuaries are highly variable environments that contain a range of important habitats, providing both optimal and sub-optimal conditions for various nektonic life-history stages. These dynamic habitats are continually altered by the effects of tides, run-off, season, and anthropogenic disturbances (Hopkinson and Vallino 1995). The value of certain estuarine habitats relative to others can be overstated, especially when nursery value for fish and crustaceans is only considered in terms of animal abundance (Beck et al. 2001). The role of aquatic vegetation in providing refuge for estuarine and marine species is of obvious benefit, however, many juvenile fish species taking refuge in vegetation emerge from this protected habitat to forage (Walters and Martell 2004). In these cases growth and survival can be closely linked to effective exploitation of non-vegetated rather than vegetated habitats. The emphasis placed on importance of submerged aquatic vegetation habitats to estuarine fauna is disproportionate to its extent within estuaries (Ruiz et al. 1993). In spite of the dominance of non-vegetated habitats in estuarine systems, few studies have focused on the importance of these habitats to estuarine systems and the fauna that reside there.

Mysid species fulfil a major role in estuarine and marine ecosystems (Roast et al. 1998; Froneman 2000; Winkler et al. 2003, 2007). Mysids are opportunistic omnivores (Mauchline 1980), and facilitate the transfer of carbon from organic detrital material and phytoplankton to zooplankton and teleost fish in estuaries. Mysids exert significant predation pressure on harpacticoid and cyclopoid copepods (Jerling and Wooldridge 1994), with these prey species also feeding on the smaller size spectrum of organic debris. A strong tendency to make dielvertical migrations in most species (Kouassi et al. 2006) often couples benthic production with pelagic ecosystems (Roast et al. 1998). In some circumstances, mysids provide a direct link between detritus and top-level estuarine predators, including financially and ecologically important species such as Australian salmon Arripis trutta (Fenton 1996), mulloway Argyrosomus japonicus (Griffiths 1997; Taylor et al. 2006), flounder Paralichthys olivaceus (Tanaka et al. 2006), herring Herklotsichthys castelnaui, yellowtail scad Trachurus novaezelandiae, sand mullet Myxus elongates, flounder Pseudorhombus sp., flathead Platycephalus sp. and whiting Sillago sp. (Pease et al. 1981). The transfer of carbon from detritus to benthic and pelagic predators is particularly important in Australian estuaries, with detritus based food webs important for carbon transfer in the face of intermittent and characteristically low inorganic nutrient inputs and limited primary productivity (Rochford 1979).

Several species of mysid exist in Australian estuaries. Of these, three are common to estuaries in south-eastern Australia. Doxomysis australiensis is a Leptomysinid occurring in estuarine and offshore waters from Sydney, New South Wales, to the Great Barrier Reef(Talbot 1997). Rhopalopthalmus egregius and Haplostylus dakini are hyperbenthic mysid species common 
in temperate Australian estuaries, although they have a smaller geographic range and more southern distribution than $D$. australiensis. Descriptions of life-history and population dynamics of all three species are absent from the literature, in spite of their high abundance in estuarine waters (Dakin and Colefax 1940); however, parallels may exist between these species and congeneric species occurring elsewhere.

The use of habitats by mysids may be related to several factors including susceptibility to predation, proximity to food supply, salinity, use of tidal currents, and diel cycles. Complex habitats are not principally chosen as a refuge from predation in mysid species, with aggregation or swarming a preferred anti-predator strategy (Flynn and Ritz 1999). Swarming in open water may not protect sympatric mysid species from predation by larger conspecifics or other carnivorous mysid species, as observed for Rhopalophthalmus terranatalis (Jerling and Wooldridge 1995); however, this may be overcome by partitioning habitat between mysid prey and potential mysid predators during periods of feeding. This paper explores this concept for three species of estuarine mysid by testing the hypotheses of no difference in size or abundance among vegetated and non-vegetated estuarine habitats, and lunar and diel phases.

\section{Materials and methods}

Study site

The present study was conducted in the Tweed River on the far north coast of New South Wales $\left(28.170^{\circ} \mathrm{S}, 153.556^{\circ} \mathrm{E}\right)$. The Tweed River catchment $\left(1100 \mathrm{~km}^{2}\right)$ supports primarily sugarcane agriculture, and includes two significant broadwaters, giving a high waterway area of $30 \mathrm{~km}^{2}$ relative to river length $(26 \mathrm{~km})$. The river contains an extensive area of wetland habitat, is a popular tourist destination, and is an important fish, prawn and oyster fishery (TSC 1996). The high agricultural land use in the river catchment leads to occasional acid sulfate soil problems, which can adversely affect riverine fauna (Sammut 2002).

\section{Sample collection and processing}

Sampling was conducted to determine mysid dynamics across a range of conditions, and use of different habitats. Over a 6-month sampling period, samples were collected on the incoming tide on every full and new moon, during the day and night. Three habitats were sampled under each set of conditions: shallow bare, deep bare and shallow vegetated, with three replicate tows undertaken in each habitat. The deep-bare habitat site was in the main river channel $\sim 7 \mathrm{~km}$ upstream from the river mouth, and consisted of a sand/silt substrate up to $10.2 \mathrm{~m}$ deep. Shallow-bare habitat site was also in the main river channel $\sim 0.5 \mathrm{~km}$ downstream from the deep-bare habitat, and consisted of sand/silt substrate up to $4.5 \mathrm{~m}$ deep. The shallow-vegetated habitat site was located outside of the main river channel immediately adjacent to the deep-bare habitat site. Vegetation consisted of dense Zostera capricorni beds in a water depth of up to $1.5 \mathrm{~m}$.

Sampling was carried out on the Tweed River between 7 October 2006 and 18 March 2007, using an epibenthic sled $(480-\mu \mathrm{m}$ mesh size, $0.7 \mathrm{~m}$ wide, $0.3 \mathrm{~m}$ high). The sled was deployed and towed over a random track at each site for up to $5 \mathrm{~min}$ (covering $<250 \mathrm{~m}$ ). Samples were collected in a 1-L sample jar connected to the cod-end of the net, and a GPS waypoint marked at deployment and retrieval of the net (accuracy of 4.5-8.0 m). Samples were fixed in $10 \%$ formalin, and salinity, temperature and turbidity measurements recorded for each tow from a Yeo-Kal water quality meter(Yeo-Kal Electronics, Brookvale, NSW, Australia).

Mysid species were sorted from sled samples in the laboratory under low power using a dissecting microscope (Olympus SZ-CTV), and stored in 95\% ethanol. Mysids were spread evenly across a glass Petri dish containing a calibration bead, and photographed with a Kodak 5-megapixel digital camera. The size of each mysid was measured automatically using the count/size function in Image Pro Plus v 4.5 (Media Cybernetics, Silver Spring, MD, USA), and then manually checked for errors. The dry weight was then calculated for each mysid using weightarea relationships, developed as follows. Up to 75 individuals for each species of mysid were randomly sampled across different sex, times, locations and size classes of organisms. Organisms were photographed as described above, and images measured for carapace length, total length and surface area using Image Pro Plus v 4.5. Each mysid was air-dried for 2 min to allow the ethanol to evaporate, wet weight was recorded, the sample was lyophilized for $72 \mathrm{~h}$, and then weighed $( \pm 1 \mu \mathrm{g})$ using a Cahn C-33 microbalance (Thermo-Fisher Scientific, Waltham, MA, USA). Regressions were developed for each species using the curve fit function in SPSS (SPSS, Chicago, IL, USA).

\section{Analysis}

Abundance and biomass measurements were standardised for tow area calculated from GPS waypoints. Non-normal data were square-root transformed before statistical analysis. Threefactor ANOVAs were conducted on abundance data for each species to test the null hypotheses of no significant difference in mysid abundance among moon (fixed, orthogonal; full and new), diel period (fixed, orthogonal; day and night), and habitat (fixed, orthogonal; shallow, seagrass or deep habitats). Two-factor ANOVAs were carried out on mean biomass measurements of the three mysid species to test the null hypothesis of no difference in mysid size among diel period, and habitat. Hochbergs analysis was used for a posteriori pairwise comparisons between factor levels. Significant interaction terms between fixed factors were evaluated using tests of simple main effects, by comparing $A$ means at each level of $B$ independently. Bray-Curtis dissimilarities were calculated for the day and night density estimates produced for each species, from which a dissimilarity matrix was generated. Clusters were generated using the unweighted pair-groups method using arithmetic averages algorithm (UPGMA). All univariate statistics were undertaken in SPSS and multivariate statistics were carried out in PRIMER v. 5.2.2 (PRIMER-E, Plymouth, UK).

\section{Results}

Temperature $\left(24.7 \pm 0.2^{\circ} \mathrm{C}\right)$, salinity $(29.1 \pm 0.2)$ and turbidity $(4.0 \pm 0.1 \mathrm{ntu}$; mean \pm s.e.) were relatively constant among sites during the sampling period (Table 1). Significant mysid weight $(\mathrm{mg})$-area $\left(\mathrm{mm}^{2}\right)$ regressions were produced for Haplostylus dakini (Weight $=0.038 \times$ Area $^{2}+0.005 \times$ Area -0.007 ; $\mathrm{r}^{2}=0.93$, d.f. $\left.=108, P<0.001\right)$, Rhopalophthalmus egregius $\left(\right.$ Weight $=0.013 \times$ Area $^{2}+0.003 \times$ Area $+0.059 ; \quad \mathrm{r}^{2}=0.91$, 
Table 1. Abiotic measurements taken at each site during the survey period

\begin{tabular}{lccccccccc}
\hline & \multicolumn{3}{c}{ Deep bare } & \multicolumn{3}{c}{ Seagrass } & \multicolumn{2}{c}{ Shallow bare } \\
& Salinity & Temp. $\left({ }^{\circ} \mathrm{C}\right)$ & Turbidity (ntu) & Salinity & Temp. $\left({ }^{\circ} \mathrm{C}\right)$ & Turbidity (ntu) & Salinity & Temp. $\left({ }^{\circ} \mathrm{C}\right)$ & Turbidity (ntu) \\
\hline Oct-06 & 28.7 & 19.6 & 3.3 & 28.5 & 21.3 & 5.3 & 29.9 & 21.1 & 2.5 \\
Nov-06 & 28.1 & 25.4 & 2.7 & 28.4 & 25.1 & 3.3 & 29.8 & 25.0 & 1.8 \\
Dec-06 & 29.3 & 24.0 & 3.2 & 28.9 & 24.1 & 4.4 & 32.7 & 24.2 & 3.4 \\
Jan-07 & 29.8 & 24.2 & 3.7 & 29.7 & 24.6 & 4.7 & 32.0 & 24.5 & 3.7 \\
Feb-07 & 28.7 & 26.7 & 4.5 & 28.3 & 26.7 & 5.3 & 31.0 & 26.9 & 5.2 \\
Mar-07 & 26.2 & 27.8 & 4.6 & 26.3 & 26.6 & 5.4 & 28.5 & 26.8 & 4.4 \\
\hline
\end{tabular}
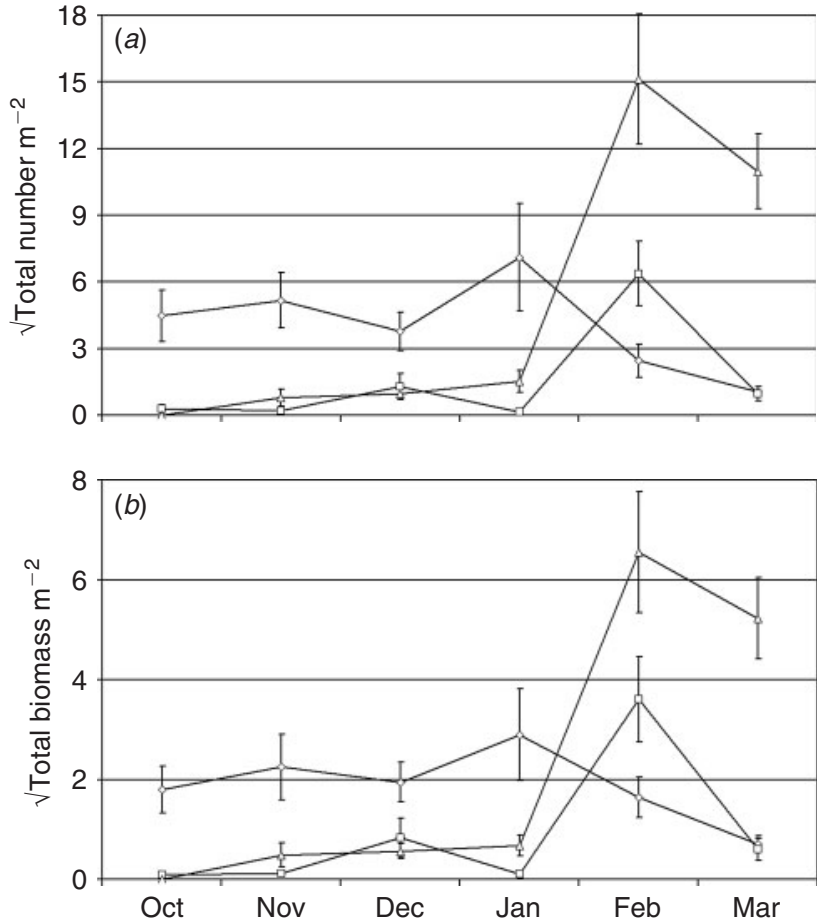

Fig. 1. Mean \pm s.e. abundance (a) and biomass (b) of Haplostylus dakini $(\diamond)$, Rhopalophthalmus egregius $(\triangle)$ and Doxomysis australiensis $(\square)$, by month.

d.f. $=76, P<0.001)$ and Doxomysis australiensis (Weight $=$ $0.055 \times$ Area $^{1.348} ; \mathrm{r}^{2}=0.93$, d.f. $\left.=77, P<0.001\right)$. The high $\mathrm{r}^{2}$ value of these regressions indicates that the body area-biomass approach developed here produces suitable accuracy for biomass calculations and inferences of population dynamics. $H$. dakini abundance and biomass were relatively stable across spring/summer but began to decline in January when $D$. australiensis and $R$. egregius began to increase (Fig. 1). $D$. australiensis and $R$. egregius abundance and biomass were low for most of spring/summer, but peaked in mid-late summer, with the greatest biomass present in the estuary in February and March (Fig. 1). Total biomass of mysid shrimp within the estuary appeared to peak in mid-late summer, with the greatest biomass present in the estuary in January and February (Fig. 1b).

Three-factor ANOVAs were conducted on abundance data for each species to test the null hypotheses of no significant difference in mysid abundance between full and new moon, day and night, and shallow bare, seagrass or deep bare habitats (Table $2 a$ ). Most of the variation in abundance of $H$. dakini was a result of diel effects $\left(F_{1,168}=33.97, P<0.001\right)$, with significantly more mysids present during the night (Fig. $2 a$ ). Subjective interpretation of a significant diel $\times$ lunar interaction (Table $2 a$ ) showed that the increase in abundance between day and night was much greater during the new moon than the full moon. Hochbergs post-hoc analysis showed significantly greater numbers of $H$. dakini were present in shallow $(P<0.001)$ and deep $(P<0.001)$ habitats than in seagrass habitats (Fig. $2 a)$, but simple main effects of a significant diel $\times$ habitat interaction term (Table $2 a$ ) showed that this relationship was not significant for daytime samples $\left(F_{2,80}=0.88, P=0.500\right)$.

There was less variation in abundance of $R$. egregius than $H$. dakini (Table $2 a$ ), with no significant difference over the diel period $\left(F_{1,168}=2.21, P=0.139\right)$. There was a significantly greater abundance of $R$. egregius present in deep water compared with shallow (Hochbergs, $P=0.001$ ) and seagrass (Hochbergs, $P=0.001$ ) habitats (Fig. $2 b$ ), and significantly greater abundance during the new moon $\left(F_{1,168}=6.51, P=0.012\right.$; Fig. 3$)$. Abundance of $D$. australiensis was significantly greater during the new moon $\left(F_{1,168}=4.08, P=0.045\right.$; Fig. 3$)$, and during the night (Table $2 a ; F_{1,168}=29.27, P<0.001$; Fig. $2 c$ ) for all habitats.

Cluster analysis produced groupings based on habitat association by the three species (Fig. 4). R. egregius day and night populations and $H$. dakini day populations were concentrated in deep water habitats, whereas $D$. australiensis and $H$. dakini night populations were concentrated in shallow habitats. The daytime D. australiensis population was most dissimilar as it was present in negligible numbers across all habitats.

Two-factor ANOVAs were carried out on mean biomass measurements of the three mysid species to test the null hypothesis of no difference in mysid size between day and night, and shallow, seagrass or deep habitats (Table $2 b$ ). There were no significant differences in $H$. dakini size within diel period; however; significantly larger $R$. egregius $\left(F_{1,95}=5.75, P=0.021\right)$ and $D$. australiensis $\left(F_{1,95}=24.12, P<0.001\right)$ individuals were present at night (Fig. 5). There were no significant differences in mysid size between habitat for any species of mysid. The trend in mysid size across time provides some evidence for multiple generations of $H$. dakini and $D$. australiensis occurring throughout the sampling period (Fig. 6), with peaks in size occurring in December and February. 
Table 2. ANOVA for abundance ( $a$ ) and mean weight $(b)$ measurements among diel period (day and night), habitat (shallow bare, seagrass and deep bare) and lunar period (full moon and new moon), for species Haplostylus dakini, Rhopalophthalmus egregius and Doxomysis australiensis MS, mean square; ${ }^{*}$ denotes significant result; ${ }^{* *}$ denotes highly significant result

\begin{tabular}{|c|c|c|c|c|c|c|c|c|c|c|}
\hline \multirow[t]{2}{*}{ Source of variation } & \multirow[b]{2}{*}{ d.f. } & \multicolumn{3}{|c|}{ H. dakini } & \multicolumn{3}{|c|}{ R. egregius } & \multicolumn{3}{|c|}{ D. australiensis } \\
\hline & & MS & $F$ & $P$ & MS & $F$ & $P$ & MS & $F$ & $P$ \\
\hline (a) Habitat & 2 & 258.03 & 8.64 & $<0.001^{* *}$ & 115.11 & 7.91 & $0.001^{* *}$ & 127.03 & 1.91 & 0.151 \\
\hline Diel period & 1 & 1014.60 & 33.97 & $<0.001^{* *}$ & 32.18 & 2.21 & 0.139 & 1945.94 & 29.27 & $<0.001^{* *}$ \\
\hline Lunar period & 1 & 19.59 & 0.66 & 0.419 & 94.76 & 6.51 & $0.012^{*}$ & 271.23 & 4.08 & $0.045^{*}$ \\
\hline Habitat $\times$ diel period & 2 & 112.77 & 3.78 & $0.025^{*}$ & 36.17 & 2.48 & 0.086 & 58.73 & 0.88 & 0.415 \\
\hline Habitat $\times$ lunar period & 2 & 12.56 & 0.42 & 0.657 & 29.25 & 2.01 & 0.137 & 2.02 & 0.03 & 0.970 \\
\hline Habitat $\times$ lunar period $\times$ diel period & 2 & 89.54 & 3.00 & 0.053 & 9.68 & 0.67 & 0.516 & 24.43 & 0.37 & 0.693 \\
\hline Error & 168 & 29.87 & & & 14.56 & & & 66.49 & & \\
\hline (b) Habitat & 2 & 0.05 & 0.31 & 0.732 & 0.01 & 0.03 & 0.971 & 0.03 & 0.70 & 0.50 \\
\hline Diel period & 1 & 0.59 & 3.56 & 0.062 & 1.15 & 5.75 & $0.021^{*}$ & 1.12 & 24.12 & $<0.001^{* *}$ \\
\hline Habitat $\times$ diel period & 2 & 0.24 & 1.42 & 0.246 & 0.20 & 0.98 & 0.38 & 0.04 & 0.84 & 0.43 \\
\hline Error & 95 & 0.17 & & & 0.20 & & & 0.05 & & \\
\hline
\end{tabular}

\section{Discussion}

The three mysid species investigated here have distinctive diel and lunar migratory behaviours and patterns of habitat use. Overall, mysid abundance was concentrated in non-vegetated estuarine habitats, irrespective of depth, with (sometimes significantly) lower abundance in seagrass. Abundances in seagrass were generally $5-30 \%$ of those recorded in bare estuarine habitats under similar conditions. The basis of this preference for non-vegetated areas instead of seagrass is most probably effective trophic use and anti-predator behaviour.

Detritivorous/phytoplanktivorous species of mysid shrimp like Haplostylus dakini may derive trophic benefits from exploiting unvegetated over seagrass habitats. Organic detritus tends to accumulate in troughs of sediment ripples within unvegetated estuarine habitat, and detrital load in these environments can be higher than that of vegetated habitats (Iwasaki 1993; Netto and Lana 1997). Detritus accumulation on bare sediments provides a concentrated food supply for these species, possibly within a habitat relatively sheltered from tidal currents. Furthermore, studies have detected greater densities of copepod prey in unvegetated habitats relative to vegetated ones (Iwasaki 1993; Netto and Lana 1997), which indicates improved forage resources for potentially carnivorous mysid species such as Rhopalophthalmus egregius in unvegetated habitats as well.

Although there is evidence supporting trophic benefits for mysid species exploiting non-vegetated habitats, the spatial heterogeneity of seagrass habitats may have a greater influence on mysid distribution. Seagrass habitat complexity does have a positive relationship with abundance of some caridean shrimp (Unsworth et al. 2007), but potentially interferes with the social organisation (swarming) and anti-predator behaviour of mysid species. Mysids are highly social species that aggregate in swarms or shoals (Ritz 2000), comprising a spatially contiguous group of conspecifics at medium to high densities. This level of organisation has evolved to enhance reproductive success and underpins the key anti-predator behaviour of this taxa (Mauchline 1980). The spatial complexity of seagrass habitats confuses this organisation and makes aggregation difficult.
Consequently the integrity of the swarm is compromised by intrusion of vegetation, thus decreasing the effectiveness of the primary anti-predator response. The efficiency of this type of organisation and distribution is evident in Australian estuaries, with mysids appearing less frequently in the diets of ambush predators (Linke et al. 2001).

\section{Seasonal dynamics}

Haplostylus dakini showed a pronounced decrease in abundance in late summer, with Rhopalophthalmus egregius and Doxomysis australiensis showing a marked increase in abundance at this time. Haplostylus spp. captured in the English Channel showed the greatest abundances during the spring (Zouhiri et al. 1998), and similarly high abundances occurred for $H$. dakini in spring and early summer. Species replacement over temporal scales observed here may be a result of intraguild predation between sympatric predatory $R$. egregius, and non-predatory $H$. dakini and D. australiensis, when the former species become more abundant in late summer; however, regular sampling over longer temporal scales is necessary to confirm this. A similar phenomenon has been observed in Gammarid amphipods Gammarus duebeni celticus and G. pulex, where intraguild predation by G. pulex on G. d. celticus leads to the rapid replacement of the latter (Dick et al. 1999). The mean individual biomass of $H$. dakini, R. egregius and D. australiensis does not form a continuing relationship with time over the sampling period. Bi- or tri-monthly peaks in mean individual biomass for $H$. dakini and D. australiensis indicate that several generations may have been sampled. Weekly sampling over longer temporal periods would also clarify these observations, and also any seasonal effects on the generation time of these mysid populations.

\section{Population structure and habitat partitioning}

Haplostylus dakini abundance was significantly greater during the night than day. Although no published research exists on this species, other Gastrosaccinidae show strong diel vertical migration (DVM, e.g. Macquartmoulin and Maycas 1995; 

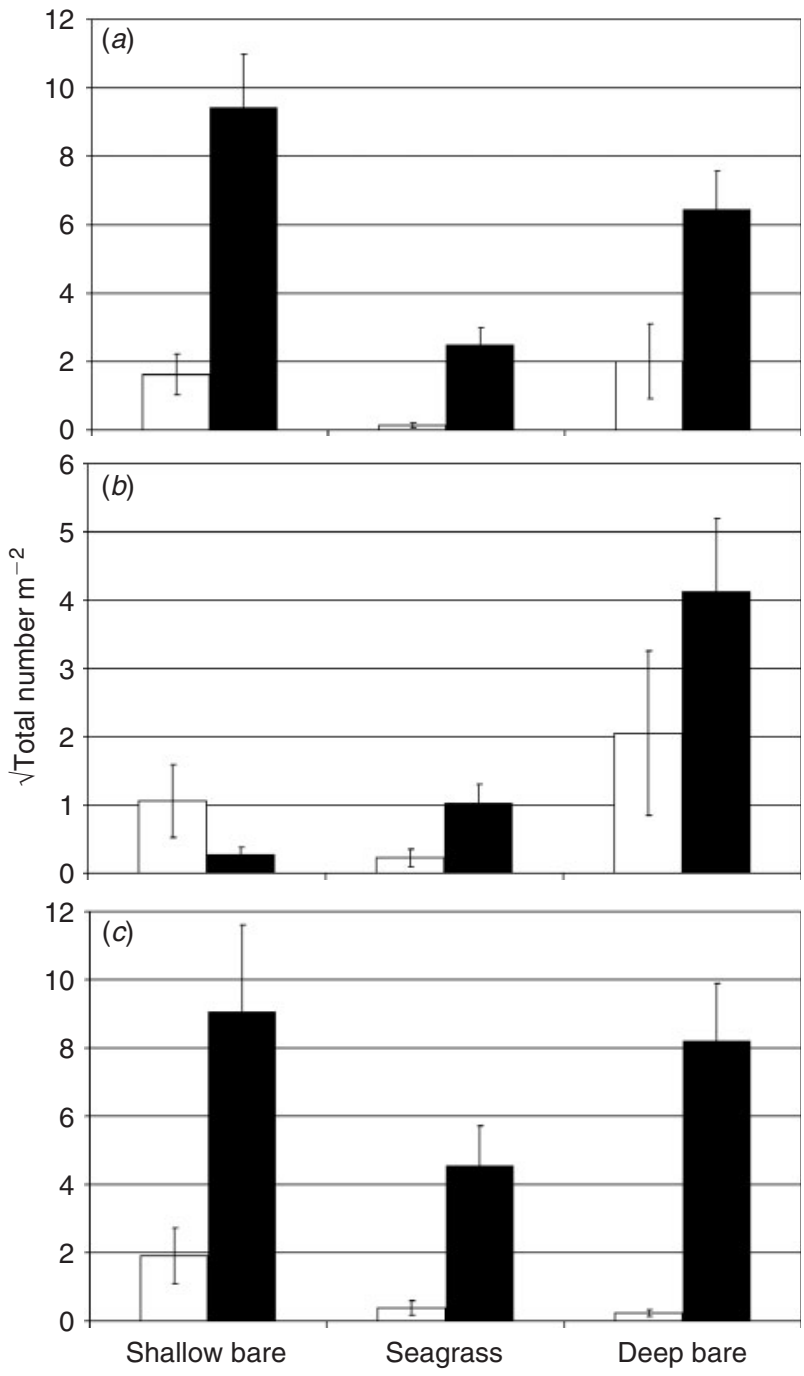

Fig. 2. Mean \pm s.e. abundance of Haplostylus dakini (a), Rhopalophthalmus egregius (b) and Doxomysis australiensis $(c)$ by habitat and diel period (day, white bars; night, black bars).

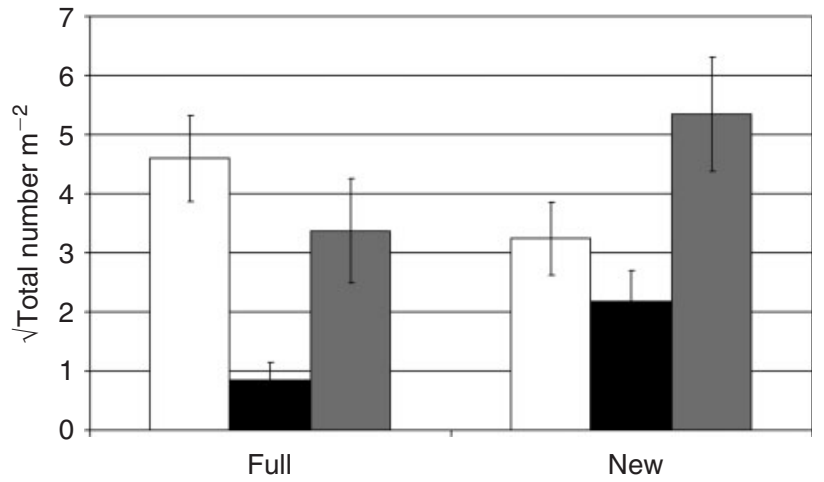

Fig. 3. Mean \pm s.e. abundance of Haplostylus dakini (white bars), Rhopalophthalmus egregius (black bars) and Doxomysis australiensis (grey bars) by lunar period.

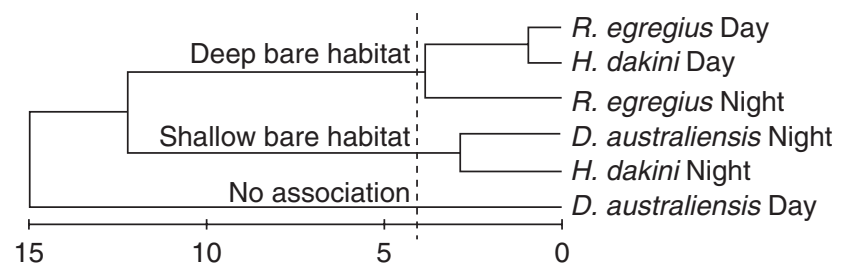

Fig. 4. Dendrogram from cluster analysis of square-root transformed abundance data for Haplostylus dakini, Rhopalophthalmus egregius and Doxomysis australiensis during the day and night. The vertical line indicates the level of dissimilarity used to separate groups by habitat association.

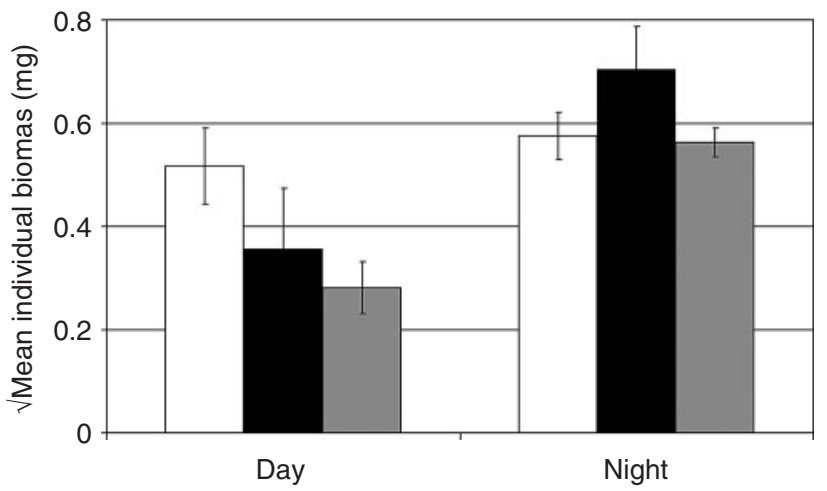

Fig. 5. Mean \pm s.e. individual biomass of Haplostylus dakini (white bars), Rhopalophthalmus egregius (black bars) and Doxomysis australiensis (grey bars) by diel period.

Zouhiri et al. 1998), burying in the sediments during the day and emerging to feed at night (Kibirige et al. 2003).

Rhopalophthalmus egregius individual mean biomass was four times greater during the night; however, there was no significant difference in abundance between day and night. This suggests there may be a juvenile and adult subpopulation partitioning their distribution, with juveniles using the hyperbenthos during the day and adults at night. This explains the surprising lack of a diel relationship for numbers of $R$. egregius, which was also observed in congeneric Rhopalophthalmus terrantalis (Wooldridge and Bailey 1982). Rhopalophthalmus spp. adults are cannibalistic (Wooldridge and Bailey 1982), and adults and juveniles have been known to segregate to minimize cannibalistic interactions (Mauchline 1980). Kouassi et al. (2006) found DVM and diurnal feeding behaviour in congeneric Rhopalophthalmus africana, with numbers of juvenile mysids at the surface peaking during the night, and adult numbers peaking during the day. In aquarium experiments, juvenile $R$. africana required a specific ingestion rate up to ten times that of adults, and the ingestion rate was five times more dependent on zooplankton concentration for juveniles, which indicates lower capture efficiency and greater handling time for juveniles. DVM of copepod prey shows that a greater concentration of zooplankton are present near the bottom during the day (Leising et al. 2005; Morgado et al. 2006; Thorisson 2006), when juvenile $R$. egregius are near the bottom. These relationships show the $R$. egregius population may be partitioning habitat to increase juvenile survival, by both minimizing intraspecific predation of adults on juveniles, and allowing the exploitation of this niche foraging 

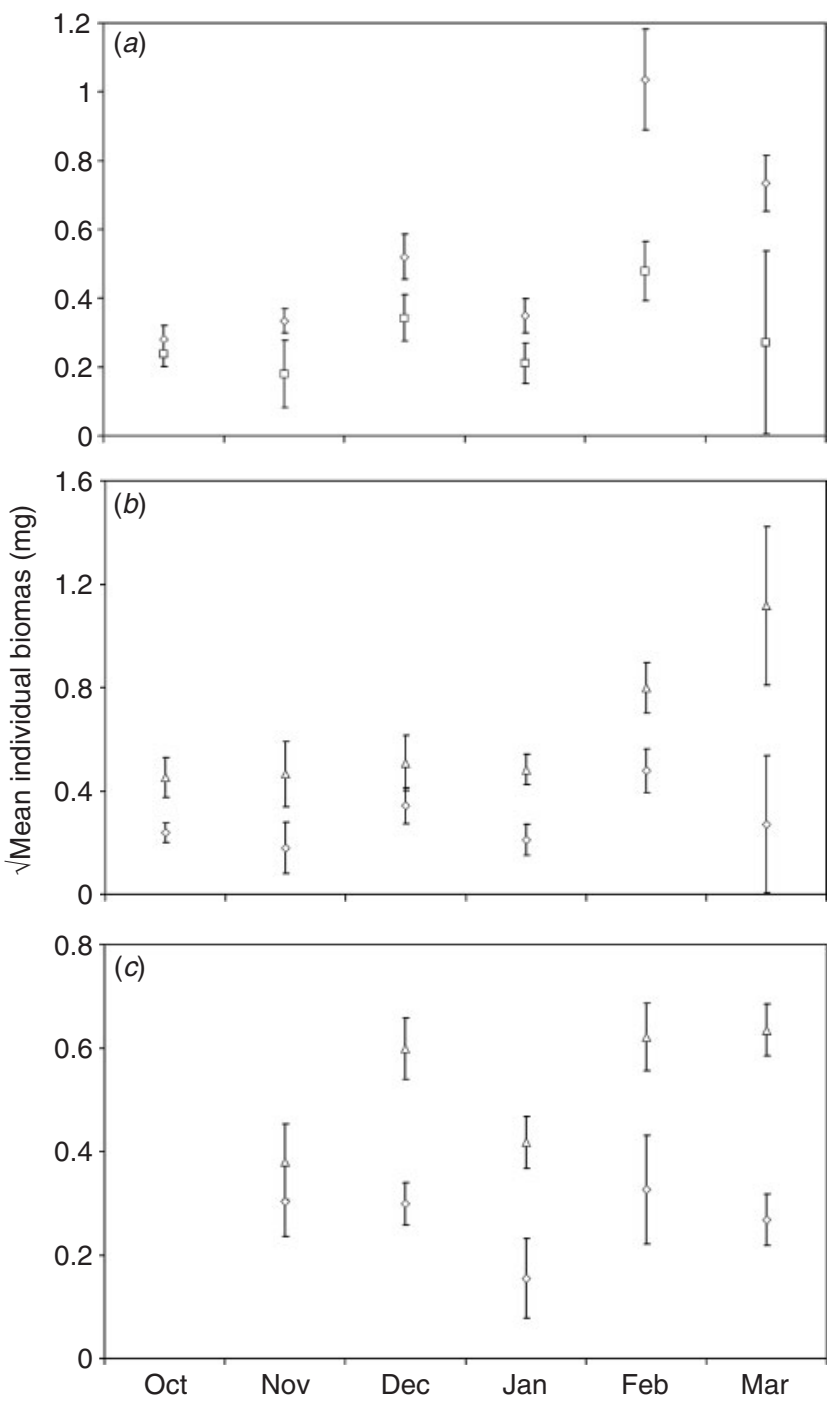

Fig. 6. Mean \pm s.e. individual biomass of day $(\diamond)$ and night $(\triangle)$ samples for Haplostylus dakini (a), Rhopalophthalmus egregius $(b)$ and Doxomysis australiensis (c), by month.

environment by juveniles at optimal prey abundance to enhance growth. The mechanisms behind the phenomena described above for $R$. egregius are the subject of research presently underway in the Georges River.

Only taxonomic information exists for $D$. australiensis; quantitative studies on the ecology of this species are lacking, as is the case for many mysid species (Wooldridge 1986). Few studies exist on members of Leptomysini in general, but other members of the tribe have been shown to be detritivorous and phytoplanktivorous (Mauchline 1980). The structure of the maxillary apparatus in this species suggests it would be good for sweeping detritus into the mouth, as well as grasping phytoplankton (S. Talbot, Australian Museum, pers. comm.). The D. australiensis estuarine population sampled in the present study comprised two size classes, with day samples characterised by negligible numbers of small mysids $\left(0.5\right.$ mysids $\left.\mathrm{m}^{-3}\right)$, and night samples being dominated by high numbers of large mysids
( $\sim 50$ mysids $\left.\mathrm{m}^{-3}\right)$. The drop in numbers and biomass of D. australiensis in March indicates a decline of the estuarine population towards the end of summer. The ubiquitous distribution of this species across estuarine, coastal and reef habitats indicates that the species may use the estuary for a limited period only, possibly to exploit a particular trophic niche, such as a summer estuarine phytoplankton bloom. This is supported by the lack of habitat preference or partitioning exhibited by $D$. australiensis relative to the other resident species, $H$. dakini and $R$. egregius.

Finally, lunar-related trends in abundance exhibited by $R$. egregius and $D$. australiensis have been observed previously in mysid shrimp. Changes in abundance during different moon phases are the result of decreased migration during moonlit phases (full moon). Kouassi et al. (2006) propose that this may be a response to avoid predation by fish.

This first study into the ecology and dynamics of mysid shrimp in Australian estuaries has shown potential habitat zonation and adaptive foraging strategies facilitating the coexistence of sympatric mysid species, $H$. dakini and $R$. egregius. Withinspecies habitat partitioning may allow juvenile $R$. egregius to minimize predation by adult $R$. egregius. Although the present study has examined dynamics in the context of the ecology of related species, future research should endeavour to establish the trophic linkages between these three species and their food using stable isotope analysis. In addition, research should also examine interactions between the three species under controlled laboratory conditions, to determine the extent of intraspecific and intraguild predation.

\section{Acknowledgements}

The author wishes to acknowledge the contributions of D. Rumbelow, K. Taylor, A. Ferguson and E. Kylberg at the University of New South Wales. Discussions with S. Talbot (Australian Museum) and I. Suthers (University of New South Wales) greatly improved the manuscript. The author also wishes to thank four anonymous reviewers and A. Boulton for their valuable and constructive comments on this manuscript. This work was undertaken with funding provided by the NSW Saltwater Recreational Fishing Trust (Grant \# L30), and sampling was conducted under NSW Department of Primary Industries Permit Number P03/0086.

\section{References}

Beck, M. W., Heck, K. L., Jr, Able, K. W., Childers, D. L., Eggleston, D. B., et al. (2001). The identification, conservation, and management of estuarine and marine nurseries for fish and invertebrates. Bioscience 51, 633-641. doi:10.1641/0006-3568(2001)051[0633:TICAMO]2.0.CO;2

Dakin, W., and Colefax, A. (1940). 'The Plankton of the Australian Coastal Waters off New South Wales, Part 1.' (Australasian Medical Publishing Company: Glebe.)

Dick, J. T. A., Montgomery, W. I., and Elwood, R. W. (1999). Intraguild predation may explain an amphipod replacement: evidence from laboratory populations. Journal of Zoology 249, 463-468. doi:10.1111/J.14697998.1999.TB01216.X

Fenton, G. E. (1996). Production and biomass of Tenagomysis tasmaniae Fenton, Anisomysis mixta australis (Zimmer) and Paramesopodopsis rufa Fenton from south-eastern Tasmania (Crustacea: Mysidacea). Hydrobiologia 323, 23-30.

Flynn, A. J., and Ritz, D. A. (1999). Effect of habitat complexity and predatory style on the capture sucess of fish feeding on aggregated prey. Journal of the Marine Biological Association of the United Kingdom 79, 487-494. doi:10.1017/S0025315498000617 
Froneman, P. W. (2000). Feeding studies on selected zooplankton in a temperate estuary, South Africa. Estuarine, Coastal and Shelf Science 51, 543-552. doi:10.1006/ECSS.2000.0700

Griffiths, M. H. (1997). Feeding ecology of South African Argyrosomus japonicus (Pisces: Sciaenidae), with emphasis on the Eastern Cape surf zone. South African Journal of Marine Science 18, 249-264.

Hopkinson, C. S., and Vallino, J. J. (1995). The relationships among mans' activities in watersheds and estuaries - a model of runoff effects on patterns of estuarine community metabolism. Estuaries 18, 598-621. doi: $10.2307 / 1352380$

Iwasaki, N. (1993). Distribution of meiobenthic copepods from various habitats in Pauatahanui Inlet, New-Zealand. New Zealand Journal of Marine and Freshwater Research 27, 399-405.

Jerling, H. L., and Wooldridge, T. H. (1994). Comparative morphology of the feeding appendages of 4 mesozooplankton species in the Sundays River Estuary. South African Journal of Zoology 29, 252-257.

Jerling, H. L., and Wooldridge, T. H. (1995). Feeding of 2 mysid species on plankton in a temperate South African estuary. Journal of Experimental Marine Biology and Ecology 188, 243-259. doi:10.1016/00220981(95)00007-E

Kibirige, I., Perissinotto, R., and Nozais, C. (2003). Grazing rates and feeding preferences of the mysid shrimp Gastrosaccus brevifissura in a temporarily open estuary in South Africa. Marine Ecology Progress Series 251, 201-210. doi:10.3354/MEPS251201

Kouassi, E., Pagano, M., Saint-Jean, L., and Sorbe, J. C. (2006). Diel vertical migrations and feeding behavior of the mysid Rhopalophthalmus africana (Crustacea: Mysidacea) in a tropical lagoon (Ebrie, Cote d'Ivoire). Estuarine, Coastal and Shelf Science 67, 355-368. doi:10.1016/J.ECSS.2005.10.019

Leising, A. W., Pierson, J. J., Cary, S., and Frost, B. W. (2005). Copepod foraging and predation risk within the surface layer during nighttime feeding forays. Journal of Plankton Research 27, 987-1001. doi:10.1093/PLANKT/FBI084

Linke, T. E., Platell, M. E., and Potter, I. C. (2001). Factors influencing the partitioning of food resources among six fish species in a large embayment with juxtaposing bare sand and seagrass habitats. Journal of Experimental Marine Biology and Ecology 266, 193-217. doi:10.1016/ S0022-0981(01)00356-2

Macquartmoulin, C., and Maycas, E. R. (1995). Inshore and offshore diel migrations in European benthopelagic mysids, genera Gastrosaccus, Anchialina and Haplostylus (Crustacea, Mysidacea). Journal of Plankton Research 17, 531-555. doi:10.1093/PLANKT/17.3.531

Mauchline, J. (1980). The biology of mysids and euphausids. In 'Advances in Marine Biology’. (Eds J. Blaxter, F. Russell and M. Yonge.) pp. 1-263. (Academic Press: London.)

Morgado, F. M., Pastorinho, M. R., Quintaneiro, C., and Re, P. (2006). Vertical distribution and trophic structure of the macrozooplankton in a shallow temperate estuary (Ria de Aveiro, Portugal). Scientia Marina 70, 177-188.

Netto, S. A., and Lana, P. C. (1997). Intertidal zonation of benthic macrofauna in a subtropical salt marsh and nearby unvegetated flat (SE, Brazil). Hydrobiologia 353, 171-180. doi:10.1023/A:1003090701675

Pease, B., Bell, J., Burchmore, J., Middleton, M., and Pollard, D. (1981). The ecology of fish in Botany Bay: Biology of commercially and recreationally valuable species. State Pollution Control Commission, BBS 23B, Sydney.

Ritz, D. A. (2000). Is social aggregation in aquatic crustaceans a strategy to conserve energy? Canadian Journal of Fisheries and Aquatic Sciences 57, 59-67. doi:10.1139/CJFAS-57-S3-59

Roast, S. D., Thompson, R. S., Widdows, J., and Jones, M. B. (1998). Mysids and environmental monitoring: A case for their use in estuaries. Marine and Freshwater Research 49, 827-832. doi:10.1071/MF97099
Rochford, D. J. (1979). Nutrient status of the oceans around Australia. CSIRO Division of Fisheries and Oceanography Report 1977-1979, CSIRO, Hobart.

Ruiz, G. M., Hines, A. H., and Posey, M. H. (1993). Shallow water as a refuge habitat for fish and crustaceans in non-vegetated estuaries: an example from Chesapeake Bay. Marine Ecology Progress Series 99, 1-16. doi:10.3354/MEPS099001

Sammut, J. (2002). Associations between acid sulfate soils, estuarine acidification, and gill and skin lesions in estuarine and freshwater fish. Dissertation Abstracts International Part B: Science and Engineering 63, 1097.

Talbot, M. S. (1997). Doxomysis acanthina, a new leptomysinid (Crustacea: Mysidacea) from the northern Great Barrier Reef, Australia, with extensions to the known distributions of D. australiensis W.M. Tattersall, 1940 and D. spinata Murano, 1990, and a key to the genus Doxomysis. Proceedings of the Biological Society of Washington 110, 426-438.

Tanaka, Y., Yamaguchi, H., Tominaga, O., Tsusaki, T., and Tanaka, M. (2006). Relationships between release season and feeding performance of hatchery-reared Japanese flounder Paralichthys olivaceus: In situ release experiment in coastal area of Wakasa Bay, Sea of Japan. Journal of Experimental Marine Biology and Ecology 330, 511-520. doi:10.1016/ J.JEMBE.2005.09.022

Taylor, M. D., Fielder, D. S., and Suthers, I. M. (2006). Spatial and ontogenetic variation in the diet of wild and stocked mulloway (Argyrosomus japonicus, Sciaenidae) in Australian estuaries. Estuaries and Coasts 29, $785-793$.

Thorisson, K. (2006). How are the vertical migrations of copepods controlled? Journal of Experimental Marine Biology and Ecology 329, 86-100. doi:10.1016/J.JEMBE.2005.08.011

TSC (1996). Upper Tweed Estuary Management Plan. Tweed Shire Council, Tweed Heads.

Unsworth, R., De Grave, S., Jompa, J., Smith, D., and Bell, J. (2007). Faunal relationships with seagrass habitat structure: a case study using shrimp from the Indo-Pacific. Marine and Freshwater Research 58, 1008-1018. doi:10.1071/MF07058

Walters, C. J., and Martell, S. (2004). 'Fisheries Ecology and Management.' (Princeton University Press: Princeton.)

Winkler, G., Dodson, J. J., Bertrand, N., Thivierge, D., and Vincent, W. F. (2003). Trophic coupling across the St. Lawrence River estuarine transition zone. Marine Ecology Progress Series 251, 59-73. doi:10.3354/ MEPS251059

Winkler, G., Martineau, C., Dodson, J. J., Vincent, W. F., and Johnson, L. E. (2007). Trophic dynamics of two sympatric mysid species in an estuarine transition zone. Marine Ecology Progress Series 332, 171-187. doi:10.3354/MEPS332171

Wooldridge, T. (1986). Distribution, population dynamics and estimates of production for the estuarine mysid, Rhopalophthalmus terranatalis. Estuarine, Coastal and Shelf Science 23, 205-223. doi:10.1016/02727714(86)90055-7

Wooldridge, T., and Bailey, C. (1982). Euryhaline zooplankton of the Sundays Estuary and notes on trohpic relationships. South African Journal of Marine Science 17, 151-163.

Zouhiri, S., Vallet, C., Mouny, P., and Dauvin, J. C. (1998). Spatial distribution and biological rhythms of suprabenthic mysids from the English Channel. Journal of the Marine Biological Association of the United Kingdom 78, 1181-1202.

Manuscript received 21 December 2007, accepted 29 June 2008 